\begin{tabular}{|c|c|c|}
\hline 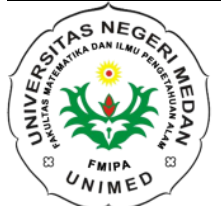 & $\begin{array}{l}\text { Jurnal Inovasi Pembelajaran Fisika } \\
\text { (INPAFI) } \\
\text { Available online http://jurnal.unimed.ac.id/2012/index.php/inpafi } \\
\text { e-issn 2549-8258, p-issn 2337-4624 }\end{array}$ & $\begin{array}{c}\text { INPAFI } \\
\\
\end{array}$ \\
\hline
\end{tabular}

\title{
PENGARUH MODEL PEMBELAJARAN INDUKTIF TERHADAP HASIL BELAJAR DAN AKTIVITAS BELAJAR FISIKA PADA MATERI POKOK TEORI KINETIK GAS DI KELAS XI SEMESTER II SMA NEGERI 15 MEDAN T.P. 2016/2017
}

\author{
Inton Dolly Panjaitan dan Abd. Hakim S \\ Jurusan Fisika FMIPA Universitas Negeri Medan \\ intondollyp2@gmail.com, abdhakims07@gmail.com
}

Diterima: September 2018. Disetujui: Oktober 2018. Dipublikasikan: Nopember 2018

\begin{abstract}
ABSTRAK
Penelitian ini bertujuan untuk mengetahui pengaruh model pembelajaran induktif terhadap hasil belajar fisika pada materi teori kinetik gas di kelas XI Semester II SMA Negeri 15 Medan T.P 2016/2017. Jenis penelitian ini adalah quasi experiment dengan desain two group pre-test-post-test. Pengambilan sampel dilakukan dengan cara random sampling dengan mengambil dua kelas dari enam kelas yaitu kelas XI IPA 2 sebagai kelas eksperimen dan kelas XI IPA 1 sebagai kelas kontrol yang masing-masing berjumlah 30 orang. Instrumen yang digunakan berupa tes hasil belajar berbentuk pilihan berganda, yang sudah divalidasi dan lembar observasi untuk mengukur aktivitas selama proses pembelajaran. Hasil penelitian menunjukkan nilai rata-rata pre-test kelas eksperimen adalah 46,97 dan kelas kontrol adalah 53,1. Setelah pembelajaran selesai diberikan post-test dengan hasil nilai rata-rata kelas eksperimen 63,93 dan kelas kontrol adalah 54,7. Hasil uji hipotesis menggunakan uji beda (uji-t) diperoleh ada pengaruh yang signifikan penerapan model pembelajaran induktif terhadap hasil belajar fisika pada materi teori kinetik gas dikelas XI Semester II SMA Negeri 15 Medan T.P 2016/2017.
\end{abstract}

Kata Kunci: model pembelajaran, induktif, hasil belajar

\begin{abstract}
This study aims to determine the effect of inductive learning model on physics learning outcomes on materials kinetic gas theory in class XI Semester II SMA Negeri 15 Medan T.P 2016/2017. The kind of research is quasi experiment by design two group pre-test-post-test. Sample interpretation was doing by random sampling with take two classes of six classes like XI IPA 2 class as experiment class that aggregate 30 peoples and XI IPA 1 class as control class that aggregate 30 peoples. Instrument that use like learning outcomes test that form multiple choice that had validity and sheet of observation to measure activity as learning process. The research result refer average pre-test value of experiment class is 46,97 and control class is 53,1 . After learning had been finished was given post-test with the result average post-test value experiment class is 63,93 and control class is 54,7 . The result hypotheses test use different test ( $\mathrm{t}$-test) there was obtained a significant influence on the application of inductive learning model to the results of physics learning on materials kinetic theory gas class XI Semester II SMA Negeri 15 Medan T.P 2016/2017.
\end{abstract}

Keyword : learning model, inductive, learning outcomes 


\section{PENDAHULUAN}

Pendidikan merupakan salah satu kebutuhan manusia. Pendidikan memiliki peran dan berpengaruh positif terhadap segala bidang kehidupan dan perkembangan manusia. Pengaruh pendidikan dapat dilihat dan dirasakan secara langsung dalam perkembangan kehidupan masyarakat, kehidupan kelompok, maupun kehidupan setiap individu. Menurut John Dewey dalam (Ahmadi, 2003 : 69) Pendidikan adalah proses pembentukan kecakapan- kecakapan fundamental secara intelektual dan emosional kearah alam dan sesama manusia.

Besarnya pengaruh pendidikan dalam kehidupan ditentukan oleh kualitas pendidikan itu sendiri. Kualitas pendidikan akan tercapai apabila proses belajar mengajar yang di selenggarakan di sekolah benar-benar efektif dan berguna untuk mencapai kemampuan pengetahuan. Salah satu masalah yang dihadapi dunia pendidikan kita adalah masalah lemahnya aktivitas belajar. Proses pembelajaran, anak kurang didorong untuk mengembangkan kemampuan berpikir.

Fisika merupakan salah satu disiplin ilmu yang berkembang sangat pesat, baik materi maupun kegunaannya. Fisika juga sebagai salah satu ilmu murni (pure science) merupakan ilmu yang sangat menunjang untuk dapat mengikuti dan mengimbangi perkembangan ilmu pengetahuan dan Teknologi (IPTEK) yang sangat global dewasa ini. Di sekolah, pelajaran fisika diajarkan dengan tujuan untuk mempersiapkan siswa agar dapat mampu menerapkan konsep-konsep fisika dalam kehidupan sehari-hari dengan melatih kemampuan dalam melakukan pengamatan, percobaan, berdiskusi, dan mengambil kesimpulan dari kegiatan-kegiatan sehari-hari. Siswa dapat menemukan, membuktikan, merealisiskan, dan mengaplikasikan suatu konsep dalam kehidupan sehari-hari. Dalam pembelajaran fisika yang di tekankan tidak hanya hasil, tetapi proses untuk mendapatkan hasil itu juga diutamakan (Giancoli, 2001).

Kegiatan belajar mengajar suatu disiplin ilmu, khususnya dalam mata pelajaran fisika, guru harus memiliki strategi mengajar yang dapat membuat siswa belajar secara aktif, efisien, dan efektif, serta tercapainya tujuan pembelajaran. Teknik penyajian pelajaran merupakan pengetahuan tentang cara mengajar yang dipergunakan guru untuk menyampaikan bahan pelajaran kepada siswa. Mata pelajaran sebaiknya guru menggunakan metode atau teknik penyajian dalam proses belajar mengajar fisika dengan metode ceramah, eksperimen, evaluasi, dan demonstrasi. Penggunaan metode atau teknik penyajian pembelajaran fisika harus mempertimbangkan kesesuaian antara metode pengajaran dan tujuan pembelajaran, materi pelajaran, media atau alat peraga, evaluasi, situasi kelas atau sekolah, serta kondisi siswa ataupun guru. Guru dapat memilih metode pembelajaran yang sesuai dengan materi ajar pembelajaran fisika untuk mencapai tujuan pembelajaran.

Permasalah yang sering terjadi dalam proses belajar mengajar adalah lemahnya aktivitas belajar dan rendahnya hasil belajar. Lemahnya aktivitas belajar dan rendahnya hasil belajar diakibatkan oleh kurangnya sumber belajar, rendahnya motivasi belajar siswa, serta adanya perbedaan intelegensi siswa. Proses belajar mengajar merupakan inti dari proses pendidikan formal di sekolah. Proses belajar mengajar akan terjadi interaksi antara siswa dengan guru. Siswa menerima bahan pelajaran, sedangkan guru mengajar dengan merangsang, membina dan mengarahkan siswa agar terjadi proses belajar yang baik sesuai dengan tujuan yang di rencanakan (Aisyah, 2016).

Berdasarkan hasil observasi peneliti ketika PPL (Program Pengalaman Lapangan) di SMA Swasta Mulia Pratama Medan menunjukkan banyak kendala siswa dalam memahami suatu konsep fisika dan menunjukkan bahwa nilai rata-rata semester siswa yang rendah. Begitu juga dengan hasil observasi saya di SMA Negeri 15 Medan dengan menjalankan angket ke siswa. Sekitar 95\% siswa tidak pernah melakukan hipotesis dalam suatu wacana dan memberi ide dalam wacana fisika. Metode yang dipakai guru cenderung menggunakan metode pembelajaran yang berpusat pada guru.

Berdasarkan masalah yang telah dikemukakan dapat diupayakan pemecahannya 
Inton Dolly Panjaitan dan Abd Hakim S, Pengaruh Model Pembelajaran Induktif Terhadap Hasil Belajar Dan Aktivitas Belajar Fisika Pada Materi Pokok Teori Kinetik Gas Di Kelas XI Semester II

SMA Negeri 15 Medan T.P. 2016/2017

yaitu dengan mencoba tindakan - tindakan yang dapat mengembangkan hasil belajar dan aktivitas belajar siswa. Salah satu model pembelajaran yang dapat digunakan adalah model pembelajaran induktif. Menurut Joyce, dkk (2011:31), model pembelajaran induktif dirancang untuk mengajari siswa dalam mencari dan mengelolah informasi, membuat dan menguji hipotesis yang menggambarkan hubungan antardata. Hasil pembelajaran utama dari model induktif melibatkan kemampuan membangun konsep siswa dengan cara menggeneralisasi, mengembangkan sikap positif terhadap objek dan menekankan adanya partisipasi siswa dalam melakukan pengamatan, dan siswa diberi kesempatan secara maksimal untuk aktif dalam pembelajaran (Biling, 2013).

Peneliti model pembelajaran induktif ini sudah diteliti oleh beberapa peneliti sebelumnya yaitu Lumbantoruan dan Ginting (2014) diperoleh terdapat peningkatan aktivitas belajar siswa selama mengikuti pembelajaran dengan menggunakan model pembelajaran induktif dengan menggunakan animasi macromedia flash berada para kriteria sedang dan pembelajaran konvensional peningkatan aktivitas berada pada kriteria rendah.

Hasil penelitian Aprillianti dan Sugiarto (2014) diperoleh hasil penelitian menunjukkan bahwa siswa telah memiliki keterampilan metakognitif sehingga dapat mencapai ketuntasan belajar dengan korelasi sebesar 1,000 dan 0,941 .

Berdasarkan kesimpulan dan saran dari peneliti sebelumnya maka peneliti tertarik untuk melakukan penelitian dengan perbedaan tempat penelitian, waktu penelitian, aspek yang dinilai yaitu hasil belajar siswa dan aktivitas belajar siswa. Peneliti akan mencoba menutupi kelemahan dari penelitian sebelumnya dengan lebih memperhatikan penggunaan waktu di dalam pembelajaran dan pengorganisasian kelompok belajar siswa.

Berdasarkan uraian latar belakang masalah di atas, peneliti tertarik melakukan penelitian dengan judul penelitian "Pengaruh Model Pembelajaran Induktif Terhadap Hasil Belajar dan Aktivitas Belajar Fisika pada Materi
Teori Kinetik Gas di Kelas XI Semester II SMA Negeri 15 Medan T.P. 2016/2017”.

\section{METODE PENELITIAN}

Populasi dalam penelitian ini adalah kelas XI SMA Negeri 15 Medan tahun pelajaran 2016/2017 sebanyak 6 kelas. Sampel penelitian terdiri dari dua kelas, kelas eksperimen yang menerapkan model induktif dan kelas kontrol dengan pembelajaran konvensional yang masing-masing berjumlah 30 orang yang ditentukan dengan metode random sampling. Instrumen penelitian yang digunakan adalah tes hasil belajar dalam ranah kognitif pada materi teori kinetik gas berjumlah 12 soal berbentuk pilihan berganda yang sudah divalidasi. Adapun desain penelitian yang digunakan dapat dilihat pada Tabel 1 .

Tabel 1.Two Group Pretest - Postest Design

\begin{tabular}{|c|c|c|c|}
\hline Kelas & Pretes & Perlakuan & Postes \\
\hline Eksperimen & $\mathrm{X}_{1}$ & $\mathrm{C}_{1}$ & $\mathrm{X}_{2}$ \\
\hline Kontrol & $\mathrm{X}_{1}$ & $\mathrm{C}_{2}$ & $\mathrm{X}_{2}$ \\
\hline
\end{tabular}

Keterangan :

$\mathrm{X}_{1}$ : pemberian pretes

$\mathrm{X}_{2}$ : pemberian postes

$\mathrm{C}_{1}$ : pembelajaran dengan menggunakan model induktif

$\mathrm{C}_{2}$ : pembelajaran konvensional

Uji beda (uji-t) digunakan untuk mengetahui pengaruh model pembelajaran terhadap hasil belajar fisika siswa dengan syarat data berdistribusi normal dan homoge (Arikunto, 2010).

\section{HASIL DAN PEMBAHASAN}

\section{Hasil Penelitian}

Penelitian ini merupakan penelitian quasi experiment yang melibatkan dua kelas, yaitu kelas eksperimen diberi perlakuan dengan menggunakan model induktif dan kelas kontrol diajarkan dengan pembelajaran konvensional. Sebelum kedua kelas diberikan perlakuan yang berbeda, kedua kelas terlebih dahulu diberikan pretes yang bertujuan untuk mengetahui kemampuan awal siswa. Berdasarkan hasil 
pretes yang diperoleh, nilai rata-rata pretes kelas eksperimen 46,97 dan nilai pretes kelas kontrol 53,10 . Selanjutnya kelas eksperimen dan kelas kontrol diberikan perlakuan yang berbeda. Setelah kedua kelas diberi perlakuan, masingmasing kelas diberi postes untuk melihat adanya perbedaan akibat diberikan perlakuan pembelajaran yang berbeda. Dari data postes kedua kelas diperoleh nilai rata-rata postes untuk kelas eksperimen sebesar 63,93 dan nilai rata-rata postes kelas kontrol sebesar 54,97. Hasil ini menunjukkan adanya perbedaan antara nilai postes kelas eksperimen dengan kelas kontrol.

Berdasarkan hasil uji normalitas dengan menggunakan uji Lilliefors untuk kedua sampel diperoleh bahwa nilai pretes dan postes berdistribusi normal seperti ditunjukkan pada tabel 2 dan tabel 3.

Tabel 2. Hasil Uji Normalitas Data Pretes

\begin{tabular}{|l|c|c|c|}
\hline \multirow{2}{*}{ Kelas } & \multicolumn{2}{c|}{ Pretes } & \multirow{2}{*}{ Kesimpulan } \\
\cline { 2 - 3 } & Lhitung & Ltabel & \\
\hline eksperimen & 0,1215 & 0,1617 & \multirow{2}{*}{ Normal } \\
\hline kontrol & 0,1361 & 0,1617 & \\
\hline
\end{tabular}

Tabel 3. Hasil Uji Normalitas Data Postes

\begin{tabular}{|c|c|c|c|}
\hline \multirow{2}{*}{ Kelas } & \multicolumn{2}{|c|}{ Postes } & \multirow{2}{*}{ Kesimpulan } \\
\cline { 2 - 3 } & Lhitung & Ltabel & \\
\hline eksperimen & 0,1117 & 0,1617 & \multirow{2}{*}{ Normal } \\
\hline kontrol & 0,1255 & 0,1617 & \\
\hline
\end{tabular}

Pengujian homogenitas dilakukan dengan menggunakan uji $\mathrm{F}$ untuk mengetahui apakah kelompok sampel berasal dari populasi yang homogen atau tidak. Hasil perhitungan uji homogenitas pretest dan postest kedua kelas sampel diringkaskan pada Tabel 4 sebagai berikut:

Tabel 4. Hasil Uji Homogenitas kelas eksperimen dan kelas kontrol

\begin{tabular}{|c|c|c|c|c|}
\hline No & Kelas & $F_{\text {hitung }}$ & $F_{\text {tabel }}$ & Kesimpulan \\
\hline 1 & Pretes & 1,0076 & & \\
\cline { 1 - 2 } 2 & Postes & 1,0380 & 1,8584 & Homogen \\
\hline
\end{tabular}

Pengujian homogenitas yang

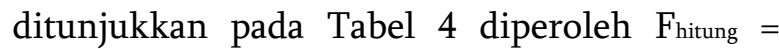
1,0076 pada pretest dan $F_{\text {hitung }}=1,0380$ pada postest, sedangkan $\mathrm{F}_{\text {tabel }}=1,8584$. Data pretest dan postest pada kedua kelas sampel menunjukkan kedua sampel homogen karena $\mathrm{F}_{\text {hitung }}<\mathrm{F}_{\text {tabel. }}$.

Hasil data pada Tabel 2 , Tabel 3 dan Tabel 4 disimpulkan bahwa data penelitian berdistribusi normal dan homogen.

Hasil uji hipotesis kelas eksprimen dan kelas kontrol ditunjukkan pada Tabel 5

Tabel 5. Hasil Uji Hipotesis Kelas Eksperimen dan Kelas Kontrol

\begin{tabular}{|c|c|c|c|}
\hline Data & thitung & tabel & Kesimpulan \\
\hline Pretes & 1,499 & 2,002 & Ho diterima \\
\hline Postes & 4,262 & 1,671 & Ha $_{\text {a }}$ diterima \\
\hline
\end{tabular}

Hasil pengujian hipotesis diperoleh bahwa untuk nilai pretes thitung $<$ tabel yaitu $1,499<2,002$ maka $\mathrm{H}_{0}$ diterima (Kriteria pengujian adalah : terima $\mathrm{H}_{\mathrm{o}}$ jika $t_{1-1 / 2 \alpha}<t<t_{1-1 / 2 \alpha} \quad$ yaitu $\quad(-2,002<1,499$ $<2,002)$ dapat disimpulkan kemampuan awal siswa pada kelas eksperimen sama dengan kemampuan awal siswa pada kelas kontrol. Hasil pengujian hipotesis diperoleh bahwa untuk nilai postes thitung $>$ tabel yaitu 4,262> 1,671 maka $\mathrm{H}_{\mathrm{a}}$ diterima. Dapat disimpulkan ada pengaruh yang signifikan antara hasil belajar siswa dengan model pembelajaran Induktif dan pembelajaran konvensional pada materi pokok Teori Kinetik Gas di kelas XI IPA semester II SMA Negeri 15 Medan T.P 2016/2017.

\section{Penilaian Sikap, Keterampilan, Aktivitas dan Tes} Hasil Belajar

Penilaian sikap diamati oleh observer selama kegiatan belajar mengajar berlangsung yang terdiri dari 3 kali pertemuan. Perkembangan rata-rata sikap siswa yang dinilai berdasarkan deskriptor dapat ditunjukkan pada Tabel 6. 
Inton Dolly Panjaitan dan Abd Hakim S, Pengaruh Model Pembelajaran Induktif Terhadap Hasil Belajar Dan Aktivitas Belajar Fisika Pada Materi Pokok Teori Kinetik Gas Di Kelas XI Semester II

SMA Negeri 15 Medan T.P. 2016/2017

Tabel 6. Perkembangan Sikap Siswa Kelas Eksperimen

\begin{tabular}{|c|c|c|}
\hline $\begin{array}{c}\text { Aspek } \\
\text { Penilaian }\end{array}$ & Deskriptor & $\%$ \\
\hline \multirow{3}{*}{$\begin{array}{c}\text { Pembentukan } \\
\text { Konsep }\end{array}$} & $\begin{array}{l}\text { 1. Memilih data, fakta } \\
\text { maupun informasi }\end{array}$ & 74,44 \\
\hline & $\begin{array}{l}\text { 2. Melanjutkan data untuk } \\
\text { klasifikasi dan komunikasi }\end{array}$ & 40 \\
\hline & $\begin{array}{c}\text { 3. Mendiskusikan } \\
\text { label/tabel pada } \\
\text { kelompok-kelompok data }\end{array}$ & 21,11 \\
\hline \multirow{3}{*}{$\begin{array}{l}\text { Interpretasi } \\
\text { Data }\end{array}$} & $\begin{array}{l}\text { 1. Mengaitkan hubungan } \\
\text { antar data }\end{array}$ & 44,44 \\
\hline & $\begin{array}{l}\text { 2. Mengintegrasikan } \\
\text { hubungan antar data }\end{array}$ & 22,22 \\
\hline & $\begin{array}{l}\text { 3. Mengusulkan } \\
\text { kesimpulan }\end{array}$ & 28,89 \\
\hline \multirow{4}{*}{$\begin{array}{l}\text { Penerapan } \\
\text { Prinsip }\end{array}$} & $\begin{array}{c}\text { 1. Merumuskan } \\
\text { konsekuensi }\end{array}$ & 17,78 \\
\hline & $\begin{array}{l}\text { 2. Mengaitkan dengan } \\
\text { fenomena } \\
\end{array}$ & 34,44 \\
\hline & 3. Mengusulkan hipotesis & 12,22 \\
\hline & 4. Menyatakan argumen & 20 \\
\hline
\end{tabular}

Penilaian keterampilan dilakukan selama kegiatan belajar mengajar yang terdiri dari tiga kali pertemuan. Hasil perkembangan keterampilan siswa dapat ditunjukkan pada tabel 7.

Tabel 7. Perkembangan Keterampilan Siswa Kelas Eksperimen

\begin{tabular}{|c|c|c|}
\hline $\begin{array}{c}\text { Aspek } \\
\text { Penilaian }\end{array}$ & Deskriptor & $\%$ \\
\hline \multirow[t]{3}{*}{$\begin{array}{c}\text { Pembentukan } \\
\text { Konsep }\end{array}$} & $\begin{array}{l}\text { 1. Menunjukkan data, } \\
\text { fakta maupun informasi }\end{array}$ & 51,11 \\
\hline & $\begin{array}{l}\text { 2. Menggunakan data } \\
\text { untuk klasifikasi dan } \\
\text { komunikasi }\end{array}$ & 34,44 \\
\hline & $\begin{array}{l}\text { 3. Membuat label pada } \\
\text { kelompok-kelompok data }\end{array}$ & 23,33 \\
\hline \multirow[t]{3}{*}{$\begin{array}{l}\text { Interpretasi } \\
\text { Data }\end{array}$} & $\begin{array}{c}\text { 1. Menunjukkan } \\
\text { hubungan antar data }\end{array}$ & 56,67 \\
\hline & $\begin{array}{l}\text { 2. Mengembangkan } \\
\text { hubungan antar data }\end{array}$ & 36,67 \\
\hline & 3. Membuat kesimpulan & 44,44 \\
\hline \multirow[t]{4}{*}{$\begin{array}{l}\text { Penerapan } \\
\text { Prinsip }\end{array}$} & $\begin{array}{l}\text { 1. Merumuskan } \\
\text { konsekuensi }\end{array}$ & 37,78 \\
\hline & 2. Menanggapi fenomena & 45,56 \\
\hline & 3. Membuat hipotesis & 10 \\
\hline & 4. Membangun argument & 45,56 \\
\hline
\end{tabular}

Penilaian aktivitas siswa tampak dalam bentuk keterampilan dan kemampuan bertindak individu. Observasi aktivitas siswa dilakukan selama proses pembelajaran berlangsung yaitu selama tiga pertemuan yang dilakukan di kelas eksperimen oleh observer yang telah dilengkapi lembar observasi.Hasil observasi aktivitas siswa dikelas eksperimen dapat dilihat pada tabel 8 .

Tabel 8. Perkembangan Aktivitas Siswa Kelas Eksperimen

\begin{tabular}{|c|c|c|}
\hline $\begin{array}{c}\text { Aspek } \\
\text { Penilaian }\end{array}$ & Deskriptor & $\%$ \\
\hline $\begin{array}{c}\text { Pembentukan } \\
\text { Konsep }\end{array}$ & $\begin{array}{c}\text { 1. Identifikasi dan } \\
\text { pencatatan }\end{array}$ & 61,11 \\
\cline { 2 - 3 } & 2. Pengelompokkan & 66,67 \\
\cline { 2 - 3 } & 3. Penamaan kelompok & 61,11 \\
\hline \multirow{4}{*}{$\begin{array}{c}\text { Interpretasi } \\
\text { Data }\end{array}$} & $\begin{array}{c}\text { 1. Identifikasi dimensi dan } \\
\text { hubungan }\end{array}$ & 28,89 \\
\cline { 2 - 3 } & 2. Menjelaskan & 33,33 \\
\cline { 2 - 3 } & 3. Membuat Kesimpulan & 50 \\
\hline Penerapan & $\begin{array}{c}\text { 1. Memprediksi } \\
\text { prinsip }\end{array}$ & 38,89 \\
\cline { 2 - 3 } & 2. Menjelaskan Fenomena & 43,33 \\
\cline { 2 - 3 } & 3. Membuat hipotesis & 20 \\
\cline { 2 - 3 } & 4. Menguji argumen & 16,67 \\
\hline
\end{tabular}

Tes hasil belajar yang didapat setelah melakukan pretes dan postes yang disusun berdasarkan taksonomi Bloom dalam ranah kognitif yaitu: Pengetahuan $\left(\mathrm{C}_{1}\right)$, Pemahaman $\left(\mathrm{C}_{2}\right)$, Aplikasi $\left(\mathrm{C}_{3}\right)$, Analisis $\left(\mathrm{C}_{4}\right)$, Evaluasi $\left(\mathrm{C}_{5}\right)$, dan Mencipta ( $\mathrm{C}_{6}$ ) dapat dilihat pada tabel dibawah ini.

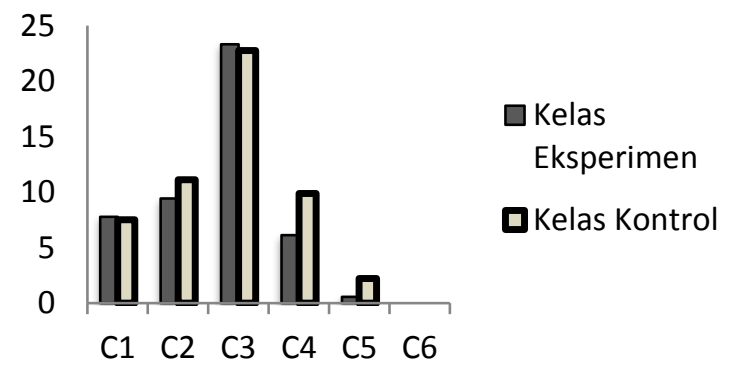

Gambar 1. Diagram batang kemampuan pretes kognitif siswa

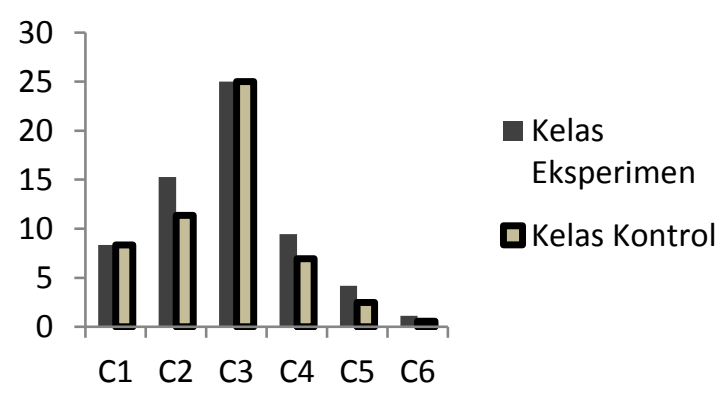

Gambar 2. Diagram batang kemampuan postes kognitif siswa 


\section{Pembahasan}

Berdasarkan hasil hipotesis yang dilakukan peneliti dengan menggunakan uji $\mathrm{t}$ maka didapat hasil thitung $=4,262$ dan tabel $=1,671$ Karena harga thitung lebih besar dari harga tabel $(4,262>1,671)$. Hal ini menunjukkan bahwa ada perbedaan yang signifikan akibat pengaruh model pembelajaran Induktif terhadap hasil belajar siswa pada materi pokok Teori Kinetik Gas di kelas XI semester II SMA Negeri 15 Medan T.P. 2016/2017. Hal ini sesuai dengan hasil penelitian terdahulu dari Lumbantoruan dan Ginting (2014) bahwa berdasarkan analisis hasil uji $t$, bahwa ada pengaruh yang signifikan terhadap penerapan model pembelajaran induktif dengan menggunakan macromedia flash.

Berdasarkan gambar diagram batang kemampuan pretest dan postes kognitif siswa (Gambar 4.8 dan Gambar 4.9), ranah kognitif C1 (Pengetahuan), C2 (Pemahaman), C3 (Penerapan), C4 (Analisis), C5 (Evaluasi), dan C6 (Mencipta) berdistribusi normal hal ini sejalan dengan hasil yang didapat peneliti sebelum menguji hipotesis menggunakan uji t bahwa data berdistribusi normal dan homogen. Hasil penelitian ini didukung oleh Pebi (2014) Pengaruh model pembelajaran berpikir induktif terhadap hasil belajar fisika siswa pada konsep getaran dan gelombang, bahwa model pembelajaran berpikir induktif dapat meningkatkan hasil belajar siswa, dimana peneliti melihat hasil belajar melalui peningkatan ranah kognitif siswa.

Berdasarkan aspek sikap (Tabel 6) persentase yang didapat siswa masih kurang baik pada pembentukan konsep, interpretasi data dan penerapan prinsip. Pada pembentukan konsep deskriptor melanjutkan data untuk klasifikasi dan komunikasi (40\%), dan mendiskusikan label/tabel pada kelompok-kelompok data $(21,11 \%)$ masih kurang sehingga peneliti tidak dapat menjalankan model pembelajaran induktif dengan maksimal. Pada Interpretasi data deskriptor mengaitkan hubungan antardata (44,44\%), mengintegrasikan hubungan antardata (22,22\%), dan mengusulkan kesimpulan (28,89\%) masih rendah sehingga peneliti belum sukses mengembangkan model pembelajaran induktif. Pada penerapan prinsip merumuskan konsekuensi mengaitkan dengan fenomena (34,44\%), mengusulkan hipotesis (12,22\%) dan menyatakan argumen (20\%) masih rendah, hal ini peneliti tidak dapat menjalankan model pembelajaran induktif dengan maksimal.

Berdasarkan aspek keterampilan (Tabel 7) persentase yang didapat siswa masih kurang baik pada pembentukan konsep, interpretasi data dan penerapan prinsip. Pada pembentukan konsep deskriptor menunjukkan data, fakta maupun informasi $(51,11 \%)$, menggunakan data untuk klasifikasi dan komunikasi $(34,44 \%)$ dan membuat label pada kelompok-kelompok data (23,33\%) masih kurang baik hal ini peneliti belum sukses menjalankan model pembelajaran induktif. Pada interpretasi data deskriptor menunjukkan hubungan antardata $(56,67 \%)$, mengembangkan hubungan antardata $(36,67 \%)$, dan membuat kesimpulan (44,44\%) masih kurang, hal ini peneliti tidak dapat menjalankan model pembelajaran induktif dengan maksimal. Pada penerapan prinsip deskriptor merumuskan konsekuensi (37,78\%), menanggapi fenomena (45,56\%), membuat hipotesis (10\%) dan membangun argumen (45,56\%) masih kurang baik, sehingga peneliti tidak dapat menjalankan model pembelajaran induktif dengan maksimal.

Berdasarkan aspek aktivitas belajar (Tabel 8) persentase yang didapat siswa masih kurang baik pada interpretasi data dan penerapan prinsip. Pada interpretasi data deskriptor identifikasi dimensi dan hubungan (28,89\%), Menjelaskan (33,33\%) dan membuat kesimpulan (50\%) kurang baik, sehingga peneliti belum sukses menjalankan model pembelajaran induktif. Pada penerapan prinsip deskriptor memprediksi konsekuensi (38,89\%), menjelaskan fenomena (43,33\%), membuat hipotesis (20\%) dan menguji argumen (16,67\%) masih kurang baik, hal ini peneliti tidak dapat menjalankan model pembelajaran induktif dengan maksimal. Hasil peneliti ini didukung Prabawati (2014) Upaya Peningkatan Aktivitas dan Hasil Belajar Siswa Melalui Penerapan Model Pembelajaran Berfikir Induktif Pada Materi Kalor Di Kelas X2 MAN 1 MODEL Kota Bengkulu, peneliti ini menyimpulkan adanya peningkatan aktivitas dan hasil belajar siswa dikelas X2 MAN 1 MODEL Bengkulu pada 
Inton Dolly Panjaitan dan Abd Hakim S, Pengaruh Model Pembelajaran Induktif Terhadap Hasil Belajar Dan Aktivitas Belajar Fisika Pada Materi Pokok Teori Kinetik Gas Di Kelas XI Semester II

SMA Negeri 15 Medan T.P. 2016/2017

konsep Kalor melalui model pembelajaran berfikir induktif, menurut pembentukan konsep, interpretasi data, dan penerapan prinsip.

Berdasarkan uji hipotesis ada perbedaan yang signifikan akibat pengaruh model pembelajaran induktif terhadap hasil belajar siswa pada materi pokok teori kinetik gas di kelas XI IPA Semester II SMA Negeri 15 Medan T.P 2016/2017. Akan tetapi tidak didukung oleh proses pembelajaran yang berlangsung seperti aspek penilaian sikap, keterampilan, dan aktivitas. Dalam hal ini Uji t belum tentu benar, karena kontrol yang tidak tepat ( variabel yang diamati tidak tepat).

\section{KESIMPULAN DAN SARAN \\ a. Kesimpulan}

Data hasil penelitian yang diperoleh dan analisa data serta pengujian hipotesis maka dapat disimpulkan (1) hasil belajar fisika siswa yang diajar dengan menggunakan model pembelajaran Induktif pada materi teori kinetik gas kelas XI IPA Semester II di SMA Negeri 15 Medan T.P. 2016/2017 memiliki nilai rata-rata sebesar 63,93 dan aktivitas belajar fisika siswa yang di ajarkan dengan menggunakan model pembelajaran Induktif pada materi teori kinetik gas kelas XI IPA Semester II di SMA Negeri 15 Medan T.P. 2016/2017 memiliki nilai rata-rata 62,11 dengan kategori cukup baik (2) hasil belajar fisika siswa yang diajar dengan menggunakan model pembelajaran langsung pada materi teori kinetik gas kelas XI IPA Semester II di SMA Negeri 15 Medan T.P. 2016/2017 memiliki nilai rata rata pretest sebesar 53,1 dan nilai rata-rata postes sebesar 54,7 (3) terdapat perbedaan yang signifikan akibat pengaruh model pembelajaran Induktif terhadap hasil belajar siswa pada materi teori kinetik gas kelas XI IPA Semester II di SMA Negeri 15 Medan T.P.2016/2017, hal ini ditunjukkan pada kelas eksperimen dengan nilai rata-rata postes 63,93 dan pada kelas kontrol memiliki nilai rata-rata postes 54,7.

\section{b. Saran}

Dari hasil penelitian yang di peroleh, maka peneliti mengemukakan saran sebagai berikut (1) Hendaknya peneliti selanjutnya berusaha menerapkan lebih baik syntaks model pembelajaran Induktif dengan berusaha meningkatkan aspek sikap, keterampilan dan aktivitas belajar siswa (2) peneliti lebih lanjut disarankan agar pengalokasian waktu yang efektif dalam menerapkan model pembelajaran Induktif sehingga seluruh kaedah-kaedah yang terdapat dalam penelitian selanjutnya dapat dilaksanakan secara optimal.

\section{DAFTAR PUSTAKA}

Ahmadi, A., (2003), Ilmu Pendidikan, Penerbit Rineka Cipta, Jakarta.

Aisyah,A.,(2016), Pendekatan Induktif untuk Meningkatkan Kemampuan Generalisasi dan Self Confident Siswa SMK, Jurnal Penelitian Pendidikan dan Pengajaran Matematikan, 2(1), : 1-12, UPI, Bandung

Aprilianti, N dan Sugiarto,B., (2014), Penerapan Model Pembelajaran Induktif Untuk Melatih Keterampilan Metakognitif Siswa Pada Materi Larutan Penyangga, Unesa Journal of Chemical Education 3(2),: 246-254, FMIPA, Unesa, Surabaya.

Arikunto, S., (2010), Prosedur Penelitian Suatu Pendekatan Praktik, Penerbit Rineka Cipta, Jakarta.

Biling, H, (2013), Effect of Inductive Thingking Model Achievement Motivation of Student in Relation to their Learning Approach, International Journal of Education and Psychological Research (IJEPR) 4(2),: 49-59, Indo Global College of Education, Abipur

Giancoli, D.C., (2001), Fisika, Edisi Kelima, Penerbit Erlangga, Jakarta.

Joyce, B., Weil, M., dan Calhoum, M., (2009), Model-Model Pembelajaran Sains, Edisi Delapan, Penerbit Pustaka Pelajar, Yogyakarta. 
Pebi, M., (2014), Pengaruh Model Pembelajaran Berfikir Induktif Terhadap Hasil Belajar Fisika Siswa Pada Konsep Getaran Dan Gelombang. Skripsi

Prabawati, R., (2014), Upaya Peningkatan Aktivitas dan Hasil Belajar Siswa Melalui Penerapan Model Pembelajaran Berfikir Induktif Pada Materi Kalor Di Kelas X2 MAN 1 Model Bengkulu T.A. 2013/2014. Skripsi

Sulastri,L dan Ginting,M.E., (2014), Pengaruh Model Pembelajaran Induktif Dengan Menggunakan Animasi Macromedia Flash Terhadap Materi Kalor Siswa Kelas VII SMP Negeri 1 Pagaran T.A. 2013/2014, Jurnal Online Pendidikan Fisika 3(2), FMIPA, Unimed, Medan 